\title{
Visual field differences in reaction times to Hebrew letters*
}

\author{
AMIRAN CARMON, ISRAEL NACHSHON, AMI ISSEROFF \\ and MURRAY KLEINER \\ Hebrew University-Hadassah Medical School, Jerusalem, Israel
}

Three experiments tested the hypothesis that visual field superiority in reaction time to verbal stimuli can be influenced by the direction of reading associated with the stimuli. Verbal reaction times were shorter for Hebrew letters that were exposed in the right rather than the left visual field, the trend being similar to that observed formerly for Arabic numerals or English letters. The effect was significant only when no knowledge about the locus of exposure was available, thus suggesting that not only cerebral dominance, but also differential attentiveness, can account for the findings.

Left hemispheric cerebral dominance for perception of speech has been investigated extensively in normal Ss by comparing reaction times in the right and the left visual fields. Several recent experiments that employed the paradigm of right and left reaction times to letters (Moscovitch \& Catlin, 1970) or to digits (Rizzolatti et al, 1971; Geffen et al, 1971) showed that those in the right visual field were shorter than those in the left visual field by 10-20 msec. This small difference was considered to reflect the time needed for the stimulus to be transmitted across the corpus callosum from the right hemisphere in order to be identified and recalled by the left hemisphere. Even nonverbal stimuli, such as dots, generated shorter reaction times when the stimulus was verbally identified from the right visual field than when it was identified from the left visual field, while manual responses to the same dots did not result in significant differences between reaction times to right or left field exposures (Filbey \& Gazzaniga, 1969). These findings lead to the conclusion that cerebral dominance can be demonstrated in normal $S s$ by comparisons of reactions times in the left and right visual fields during identification of verbal stimuli or during verbal responding to nonverbal stimuli. Another type of nonverbal stimulus, faces, which generated shorter reaction time in the left visual field with manual responses (Rizzolatti et al, 1971; Geffen et al, 1971), did not yield consistent differences between the two fields in verbal reaction times. This implies that the right hemispheric dominance effect in

* This study was supported by a grant from the Israel Ministry of Education. Requests for reprints should be addressed to Dr. Amiram Carmon, Aranne's Laboratory of Human Psychophysiology, Hadassah University Hospital, Jerusalem, Israel. face recognition, a well known clinical phenomenon, is cancelled by the left hemisphere, which controls the verbal response.

Measurements of recall of tachistoscopically presented verbal material did not yield identical results to those obtained with reaction times. Although single Latin script letters or words have generally been found to be recalled with fewer errors from the right field (White, 1969), Yiddish and Hebrew words have sometimes been found to be better recalled from the left field, or equally well from both when exposed horizontally in one field at a time (Mishkin \& Forgays, 1952; Orbach, 1953; Orbach, 1967). Since Yiddish and Hebrew words are read in a direction opposite to that for English words and since mirror images of English words also resulted in left-field superiority (Harcum \& Finkel, 1963; Harcum, 1966), it is possible that the differential recall in the two visual fields is influenced by differential scanning tendencies induced by reading habits and not by hemispheric specialization.

Since all studies that demonstrated shorter reaction times for verbal stimuli in the right visual field used single-field presentation of verbal material that is read from left to right (i.e., the same material that is recalled better from the same field under similar conditions), the question arises whether these findings can also be attributed to scanning tendencies and not to cerebral dominance.

The present series of experiments attempted to answer this question by measuring the reaction times of the right and left fields to Hebrew letters, i.e., to verbal stimuli that are not associated with right visual field superiority of recall.

\section{GENERAL METHOD}

The stimuli were Hebrew letters photographed on $35-\mathrm{mm}$ slides, with each letter appearing twice but on different slides, once to the right and once to the left of center. The slides were projected on a rear-view screen by a Kodak Carousel 800 projector equipped with an electronic shutter. Letters subtended $3 \mathrm{deg}$ and were projected $8 \mathrm{deg}$ horizontally off a central fixation point. In Experiment 1, this point was a fixed 1-deg luminous square. In Experiments 2 and 3 , the fixation point was a small circular light extending $1 \mathrm{deg}$. The slide projector, shutter, and fixation light were controlled by Massey Dickinson logic modules. On every trial the fixation light was illuminated first for $1 \mathrm{sec}$, followed then by exposure of the slide for $100 \mathrm{msec}$. Interstimulus interval was $8.5 \mathrm{sec}$ in Experiments 1 and 2 and 4 sec in Experiment 3. The Ss responded by identifying the letter vocally. Responses activated a throat microphone and stopped a millisecond counter that was started by the stimulus onset. Ss were instructed to hold their breaths on appearance of the fixation light in order to decrease variability in the vocal RT. In Experiment 3, RTs were fed on-line into an HP computer that provided continuous display of the results and permitted immediate analysis of data. Experiment 1 followed the Moscovitch \& Catlin (1969) method in which Ss were aware of the stimulus location in the visual field and in which no warning signal was employed. Experiments 2 and 3 were conducted so that stimuli appeared either in the right or in the left visual field, without the Ss' prior knowledge. The random presentation was similar to that employed by Geffen et at (1971) and by Rizzolatti et al (1971).

\section{EXPERIMENT 1}

Stimuli were arranged in different blocks, each containing 28 slides with single letters exposed to one visual field only. The letters that appeared in one field were identical to the letters that appeared in the other field. The Ss were notified before each block as to which field the letters would be projected in, and they were also instructed to fixate on the center of the screen before exposure. Ss were tested in four consecutive daily sessions. Each session comprised six alternating blocks, three to the right and three to the left visual field. On Days 1 and 4 , the first block was to the right field, and on Days 2 and 3, the first block was to the left field. Prior to each session, two blocks, one to the right and one to the left, were given for practice.

Whenever a letter was identified erroneously, it was presented again at the end of the block. Altogether, 672 reaction times, 336 exposures in each field, were measured for each $\mathrm{S}$. Ss 


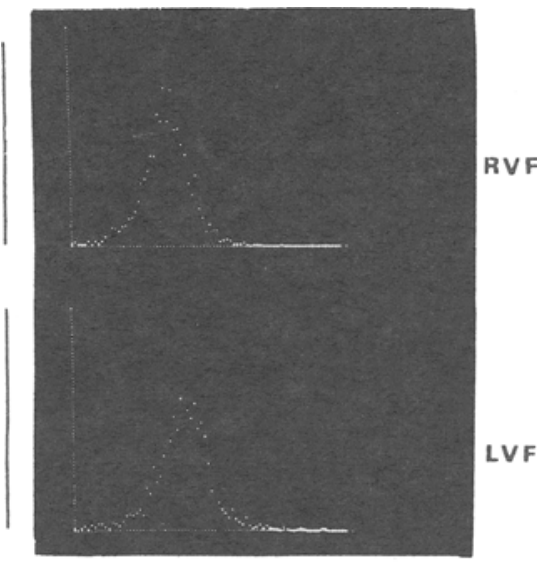

$200 \quad 400 \quad 600 \quad 800 \mathrm{msec}$

Fig. 1. Computer display of cumulative distributions of right- and left-field reaction times to Hebrew letters.

were five right-handed Israeli-born students.

Results

Mean reaction time was $311 \mathrm{msec}$ in the right and $318 \mathrm{msec}$ in the left visual field. Four of the five Ss had shorter reaction time in the right field, while the remaining $S$ had shorter reaction time in the left field. The effect of visual field on reaction time was not significant $[F(1,4)=3.34$, p $>.25]$. Reaction time decreased with practice $[F(3,12)=11.55$, $\mathbf{p}<.01]$, but the Practice by Field interaction was not significant $[F(3,12)=1.19]$.

\section{EXPERIMENT 2}

Since most Ss recognized Hebrew letters faster in the right than in the left visual field, the findings of Experiment 1 suggested that responses for verbal stimuli are faster from the right than from the left visual field, disregarding associated reading habits. However, the results were not consistent and were not statistically significant. The small magnitude of reaction time difference and the lack of statistical significance could be attributed to the method of presentation in which Ss were aware of where the letter would appear. Simon (1967) showed that right-ear superiority in reaction time could be abolished when $\mathrm{S}$ had prior knowledge about the side on which the stimulus would appear. Therefore, a second experiment was conducted in which no such information was available to S.

\section{Method}

The same stimuli were used, with the exception of one pair of letters that was damaged. Thirteen right- and 13 left-positioned letters were arranged in a random order in the same block. Six blocks of 26 letters were administered to each of six right-handed Israeli-born $S$ s in a Latin-square design. The same procedure, but with different orders of blocks, was repeated for six consecutive daily sessions. Prior to each session, one block was given as a warm-up but not included in the final analysis. Altogether, 936 letters were presented, 468 to each visual field.

\section{Results}

Reaction times were shorter to letters exposed in the right field (mean: $428 \mathrm{msec}$ ) than to letters exposed in the left field (mean: $453 \mathrm{msec})$. The difference was significant at the .001 level $[F(1,5)=$ 69.641. Though there was a slight, but significant, decrease of reaction time over sessions $[F(5,25)=2.93$, $\mathrm{p}<.025]$, the practice effect did not influence the $R-L$ differences significantly $[F(5,25)=1.03]$. Five out of the six Ss responded faster in the right than in the left field in all sessions, while the sixth $\mathrm{S}$ had shorter reaction time in the right field in only half of the sessions.

\section{EXPERIMENT 3}

Experiment 2 provided further confirmation of the results of Experiment 1, but since Experiments 1 and 2 differed in the magnitude of difference between reaction times associated with the two fields, it was decided to repeat Experiment 2 and to analyze not only the differences between means, but also to compare the total distributions of reaction times in the two fields. A modification that was introduced in this experiment was the use of a shorter interstimulus interval ( $4 \mathrm{sec}$ ) since Ss complained of fatigue due to its length. The computer made the results immediately available to $E$. As the results were identical in trend in four sessions, it was decided that further accumulation of data was of no interest.

\section{Results}

Reaction times were shorter in the right field by $29 \mathrm{msec}$ in comparison to reaction times in the left field. The respective means were 389 and $418 \mathrm{msec}$. This difference was significant $[F(1,5)=15.40, p<.025]$, as was the slight reduction of response length over sessions $[F(3,15)=3.56$, $\mathbf{p}<.05]$. The effect of practice did not interact with the effect of visual fields $[F(3,15)=1.0]$. All Ss in all sessions had faster responses in the right visual field. Cumulative histograms of reaction times produced by the computer display showed that not only were the means different in the two visual fields, but also the entire distribution of right-field reaction times was shifted by about $20 \mathrm{msec}$ from that of left-field reaction times (cf. Fig. 1) DISCUSSION

The present study extended the findings of right visual field superiority in reaction times to visual verbal stimuli by demonstrating that the effect is not dependent on the script's directional characteristics. The magnitude of this superiority was similar to that found in prior experiments and was related to the mode of presentation. When information about stimulus location was available to $S s$, this superiority was smaller than when Ss were not informed about the field of exposure. Moscovitch \& Catlin (1969) found a mean median difference in reaction time (for their right-handed Ss) of 10.6 msec favoring the right field in an experiment where letters were displayed to each visual field in separate blocks. In the present study, a mean difference of $6.5 \mathrm{msec}$ was found under similar presentation mode. Differences found in a mixed mode of presentation were usually larger. Rizzolatti et at (1971) found a difference of $18.5 \mathrm{msec}$ in favor of the right field for manual responses to letters presented randomly to the left or right fields. Vocal responses were faster by 33 msec to dots presented in the right field than to dots presented in the left field (Filbey \& Gazzaniga, 1969). Geffen et al (1971), on the other hand, employing a procedure of mixed presentation, found a 10-msec difference, but they employed longer exposure time $-160 \mathrm{msec}$ vs $100 \mathrm{msec}$ in all other cited studies. The 25 - and 29-msec differences found in Experiments 2 and 3 , respectively, in which stimuli were exposed randomly to the two fields, might indicate that expectancy minimizes RVF preference, while the direction of the effect is stable whether vocal responses, verbal stimuli, or both are used. The stability of the right field superiority in reaction times associated with verbal stimuli or responses is illustrated again by additional comparison of methods employed in different experiments. This field preference was found for stimuli exposed in a relatively wide sector of the visual field, ranging from $1 \mathrm{deg}$ off center in Filbey \& Gazzaniga's (1969) study to $8 \mathrm{deg}$ off center in the present experiment.

The interpretation of this effect in anatomophysiological terms is not a simple one. Filbey \& Gazzaniga (1969) and Moscovitch \& Catlin (1969) implied that the effect was probably due to the necessary passage of information from the right hemisphere across the corpus callosum in order to be verbally identified and recalled by the left (dominant) hemisphere. The results of the present study raise two 
questions in regard to this explanation. First, why should this physiological mechanism be affected by S's prior knowledge about the field in which the information will appear? If at least a part of the effect is due to differential attentiveness in the two visual fields, then the reduction in $L-R$ difference in reaction time that is associated with prior knowledge can be accounted for. Second, why is the magnitude of the effect not affected by displaying the information at various distances off center if it demonstrates transcallosal transfer? Though the vertical meridian from which transcallosal visual fibers originate extends about $20 \mathrm{deg}$ off center (Berlucchi et al, 1971; Whitteridge, 1965), it is difficult to assume that callosal passage time from a point that is 1 deg off center will be nearly the same as from a point that is 8 deg off center.

Finally, though the present investigation demonstrated that right visual field superiority in reaction time i s not de pendent on stimulus-associated reading habits in the same way as superiority in recall, the scanning tendency hypothesis of Heron (1957) cannot be entireiy excluded. This last hypothesis should be considered for reaction time differences in the visual fields until tested for mirror images of English words, similar to those used by Harcum (1966).

\section{REFERENCES}

BERLUCCHI, G., HERON, W., HYMAN, R., RIZZOLATTI, G., \& UMILTA, C. Simple reaction times of ipsilateral and contralateral hand to lateralized visual stimuli. Brain, 1971, 94, 419-430.

FILBEY, R. A., \& GAZZANIGA, M. S. Splitting the normal brain with reaction time. Psychonomic Science, 1969, 12, 335-336.

GEFFEN, G., BRADSHAW, J. L., \& WALLACE, G. Interhemispheric effects on reaction time to verbal and nonverbal stimuli. Journal of Experimental Psychology, 1971, 87, 415-422.

HARCUM, E. R. Visual hemifield differences as conflicts in direction of reading, Journal of Experimental Psychology, 1966, 72, 479-480.

HARCUM, E. R., \& FINKEL, M. E. Explanation of "Mishkin and Forgays' result as a directional reading conflict. Canadian Journal of Psychology, 1963, 17, 224-234.
HERON, W. Perception as a function of retinal locus and attention. American Journal of Psychology, 1957, 70, 38-48.

MISHKIN, M. \& FORGAYS, D. G. Word recognition as a function of retinal locus. Journal of Experimental Psychology, $1952,43,43-48$.

MOSCÓVITCH, M., \& CATLIN, J. Interhemispheric transmission of information: Measurement in normal man. Psychonomic Science, 1970, 18, 211-213.

ORBACH, J. Retinal locus as a factor in recognition of visually perceived words. American Joumal of Psychology, 1953, $65,555-562$.

ORBACH, J. Differential recognition of Hebrew and English words in right and left visual fields as a function of cerebral dominance and reading habits. Neuropsychologia, 1967, 5, 127-134.

RIZZOLATTI, G., UMILTA, C., \& BERLUCCHI, G. Opposite superiorities of the right and left cerebral hemispheres in discriminative reaction time to physiognomical and alphabetical material. Brain, 1971, 94, 431-442.

SIMON, J R. Ear preference in a simple reaction time task. Journal of Experimental Psychology, 1967, 75, 49-55.

WHITTERIDGE, D. Area 18 and the vertical meridian of the visual field. In $\mathbf{E}$. G. Ettlinger (Ed.), Functions of the corpus callosum. London: Churchill, 1965. Pp. 115-120.

WHITE, $M, J$. Laterality differences in perception: A review. Psychological Bulletin, 1969, 72, 387-405. 